\title{
Modeling and Simulation of a Control Algorithm for Home Energy Management System
}

\author{
Nisha.V, V.Vasudevan, A.Ramkumar
}

\begin{abstract}
Microgrids are handy units for a utility since their units such as distributed energy resources (DER) and loads can able to control the power ingestion or production. Moreover, it is used to assimilate renewable energy resources (RES) to small distribution systems. Battery energy storage systems (BESSs) are employed to recompense the sporadic output of RES. Similarly, DC microgrid for a home can be excellently controlled by an energy management system (EMS) using fuzzy logic controller (FLC) of 25-rules alone to control the power flow. The system has photovoltaic (PV), Fuel Cell (FC) and battery energy storage (BES). This study aims to introduce firefly algorithm (FA) to optimize FLC in order to increase the system energy saving efficiency and to reduce the cost.
\end{abstract}

Keywords : BES, microgrid, EMS, FLC, FA

\section{INTRODUCTION}

Over dependence on fossil fuels would led to energy crisis. So, it is essential to identify eco-friendly and nonexhausted energy source and it is vital to initiate apt energysaving methodologies to decelerate the energy consumption and to mitigate the environment impacts. Energy monitor and control have more attention for research [1], but a multifunction EMS is still inattentive. Hence, in this study, a cohesive EMS with the tasks of energy monitor and control has been presented.

Previously, advanced metering infrastructure (AMI) [2], smart sensor [3], smart home machines [4], home area network (HAN) [5] and home energy storage system (HESS) [6] have been introduced. Smart Home Energy EMS at a home can avoid redundant power consumption, enhance safety. Energy conservation and emission minimization are the ultimate objectives of EMS.

Management (SHEM) deals with the utilization of supervisory control and data acquisition system (SCADA) with EMS, comprising the generation, transmission and distribution systems under the idea of smart grid. SHEM is employed to visualize home RES because of the emerging anxieties on energy safety and pollutant emissions. Along with smart schemes SHEM can be installed at home and so as to improve efficiency [7]. Moreover, SHEM intends to perform demand side management (DSM) to deliver lenience to the utility and the consumers [8]. This study aims to design and develop of a residential microgrid with FLC. The system consists of PV, FC and BES. 25 fuzzy rules have been augmented by FA to improve efficiency with the aim of energy conservation. FA attains the best values of scaling factors and membership functions of FLC

\section{MATHEMATICAL MODEL OF THE MICROGRID}

The modules of a microgrid have been illustrated in Figure 1. The power electronic components buck/boost converters, MPPT and inverters are assembled to build the microgrid system

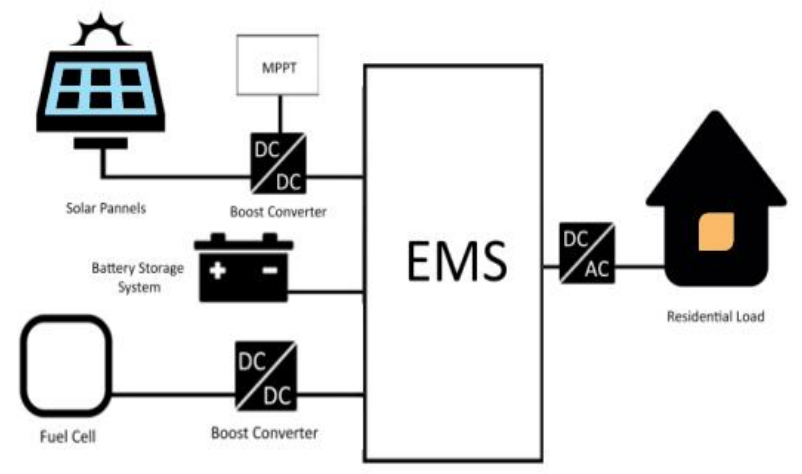

FIG. 1. STRUCTURE DIAGRAM OF A MICROGRID

\section{A. Modeling of PV system}

The equivalent circuit of PV system has been shown in Figure 2. It has a current source, a diode, series and shunt resistances. The intensity produced current of the solar cell is denoted as current, the nonlinear impedance is denoted by a diode, internal electrical losses are denoted by series resistance and shunt resistance represents the leakage current. When the intensity from sun falls on cell, DC power generated that differs gradually with the intensity of sun

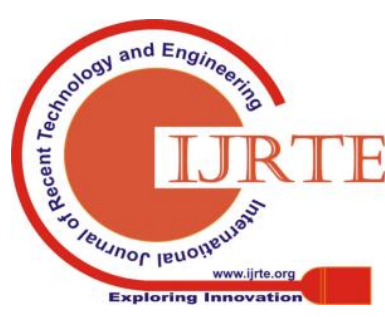




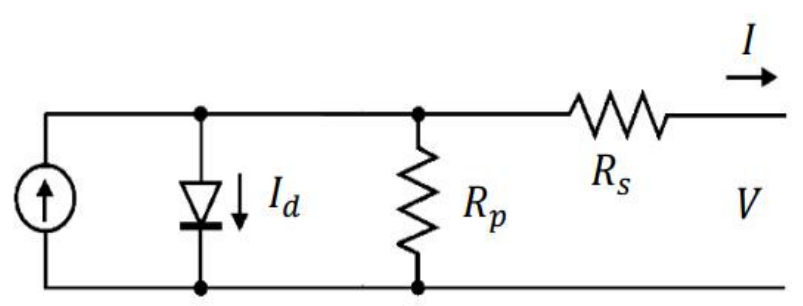

FIG. 2. EQUIVALENT CIRCUIT OF PV SYSTEM

Using Kirchhoff's current law

$$
I=I_{p h}-I_{d}-I_{s h}
$$

The photovoltaic current that alters with the intensity and temperature of sun have been provided as follow

$I=I_{p h}-I_{s}\left[\exp \frac{\left(V+I R_{s}\right) q}{a k T N_{s}}-1\right]-\frac{V+I R_{s}}{R_{s h}}$

$$
I_{p h}=I_{r} \frac{I_{s c}}{I_{r 0}}
$$

$$
I_{s}=\frac{I_{s c}}{\exp \left(\frac{V_{o c}}{a V_{t}}\right)-1}
$$

$$
I_{d}=\frac{I_{s}}{\exp \left(\frac{V+I R_{s}}{a V_{t}}\right)-1}
$$

$$
I_{s h}=\frac{V+I R_{s}}{R_{s h}}
$$$$
V_{t}=\frac{k T N_{s}}{q}
$$

$$
S O C=100\left(1-\frac{\int_{0}^{t} i d t}{Q}\right)
$$

where
i battery current
Q maximum capacity

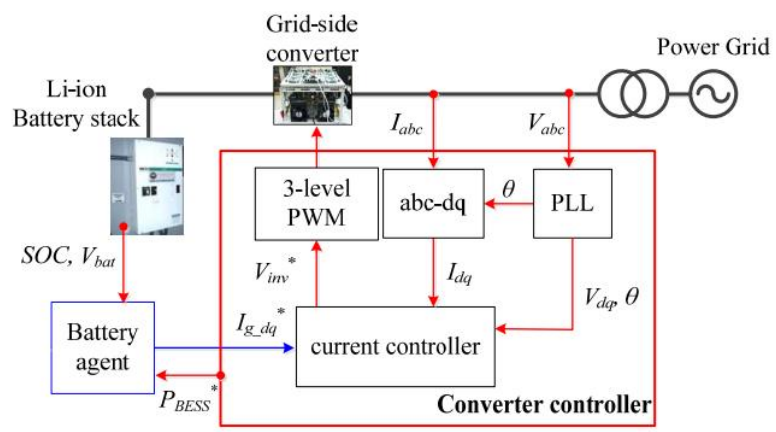

FIG. 3. EQUIVALENT CIRCUIT OF BES

\section{EMS OF THE MICROGRID}

The power electronics components of microgrid have been modeled in MATLAB. The simulation diagram of proposed EMS has been illustrated in Figure 4. FLC has been modeled with least fuzzy rules to minimize the intricacy.

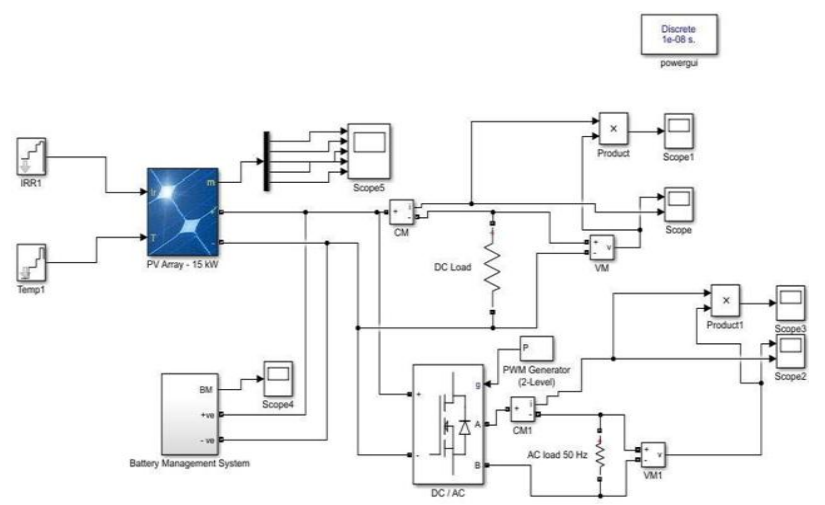

Fig 4. SIMULINK DIAGRAM OF PROPOSED EMS

\section{A. Description of the microgrid}

A $5 \mathrm{~kW}$ of PV system has been interlinked with power electronic components namely DC/DC boost converter, MPPT, etc. $20 \mathrm{kWh}$ capacity of Li-ion BES has been utilized. The FLC modeled for EMS has been shown in Figure 5. SOC and the power difference have been set as the two input variables.

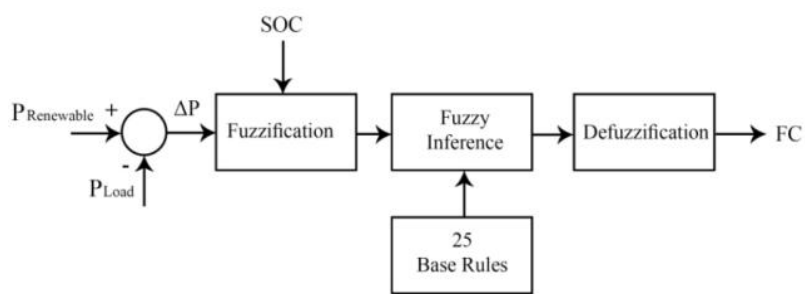

FIG 5. STRUCTURE OF FLC MODELED FOR EMS

$\Delta \mathrm{P}$ signifies the power difference between produced power from PV power and load during 24 hours.

$$
\Delta p=P_{\text {Renewable }}-P_{\text {load }}
$$

where

$P_{\text {Renewable }} \quad$ Solar power 
$P_{\text {load }}$

power of the residential load

FLC tends to compensate the intermittency of RES and to keep SOC as least as possible. The operational range of BES is $20-95 \%$ of its SOC. Table 1 provides the 25 fuzzy rules of FLC. VL, L, M, H, VH signify very low, low, medium, high and very high respectively and the $\mathrm{BN}, \mathrm{SN}, \mathrm{ZE}, \mathrm{SP}, \mathrm{BP}$ signify big negative, small negative, zero, small positive and big positive respectively.

The optimization of FLC has been performed to enhance the performance and energy saving. Controlling BES according with altering loads with least number of fuzzy rules is a difficult task. Hence, the optimization of FLC need to be performed using intelligent technique. FA, a recent and successive optimization technique has been utilized. The steps involved in the implementation of FA has been directly adopted from [10]. The error between present and actual power need to be minimized.

\begin{tabular}{|c|l|l|l|l|l|l|}
\hline \multirow{4}{*}{ SOC } & \multirow{2}{*}{$\begin{array}{c}\text { FC } \\
\text { Power }\end{array}$} & \multicolumn{5}{|c|}{$\Delta \mathbf{P}$} \\
\cline { 2 - 7 } & VL & VH & SN & ZE & SP & BP \\
\cline { 2 - 7 } & L & H & M & VL & VL & VL \\
\cline { 2 - 7 } & M & VL & VL & VL & VL & VL \\
\cline { 2 - 7 } & H & VL & VL & VL & VL & VL \\
\cline { 2 - 7 } & VH & VL & VL & VL & VL & VL \\
\hline
\end{tabular}

TABLE I. 25 FUZZY RULES OF FLC

$\min f=\int_{0}^{T}|\Delta e|^{2} d t$

where

$\mathrm{T}$ execution time

$\Delta \mathrm{e}$ error between FC produced power and reference power

$\Delta P=P_{\operatorname{Re} f}-P_{F C}$

where

$P_{F C} \quad$ FC power

$P_{\text {Ref }}$ reference power

$P_{\mathrm{Re} f}=\left\{\begin{array}{cc}P_{\text {Load }}-P_{\mathrm{Re} \text { newable }}-P_{\text {BES }}, P_{\text {Load }} \geq P_{\mathrm{Re} \text { newable }} \\ 0 & \text { Otherwise }\end{array}\right.$

where $P_{B E S}$ is the power availed in BES.

\section{RESULTS AND DISCUSSION}

The rated power generated by solar PV under idyllic weather; $1000 \mathrm{~W} / \mathrm{m}^{2}$ of irradiation, and $25^{\circ} \mathrm{C}$ of temperature. During the unavailability of solar PV and the lowest FC capacity level the BES tends to meet the demand. The load for the considered residence for a day has been illustrated in Figure 6. The data of solar irradiation and temperature for producing power to meet the load has been shown in Figure 7. The SOC characteristics of BES has been exposed in Figure 8 . The details of energy investigations and the energy saving potentials of the proposed system have been presented in Table 2.

FIG 6 LOAD OF THE RESIDENCE FOR 24 HOURS

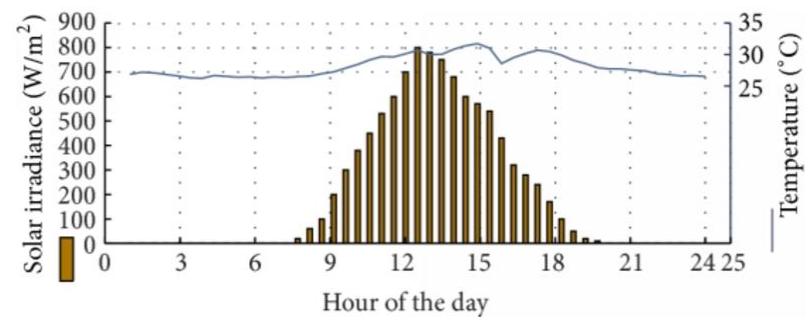

FIG 7. DATA OF SOLAR IRRADIATION AND TEMPERATURE FOR 24 HOURS

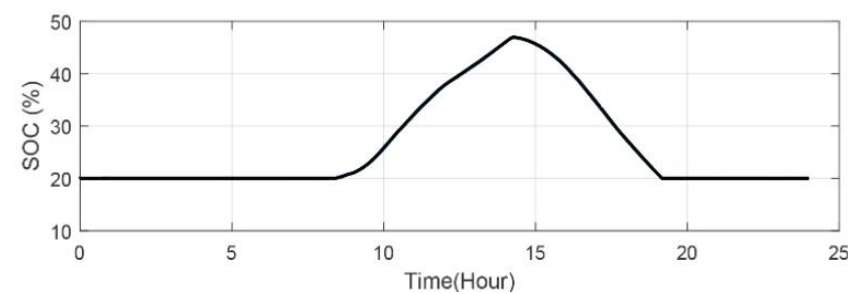

FIG 8.SOC CHARACTERISTICS OF BES

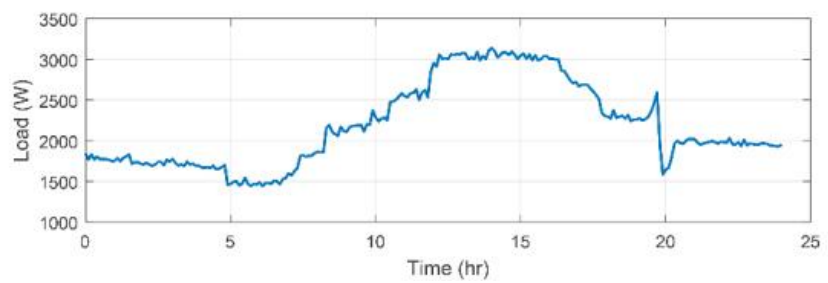

TABLE II. DETAILS OF ENERGY INVESTIGATIONS AND ENERGY SAVING POTENTIALS

\begin{tabular}{|l|l|}
\hline \multicolumn{1}{|c|}{ Factor } & \multicolumn{1}{c|}{ Energy } \\
\hline Load & $50.41 \mathrm{kWh}$ \\
\hline Solar Power & 30.54 \\
\hline Fuel cell (with normal FLC) & 27.14 \\
\hline Fuel cell (with optimal FLC) & 20.78 \\
\hline Without optimization & $85.27 \%$ \\
\hline With FA optimization & $96.24 \%$ \\
\hline
\end{tabular}

\section{v CONCLUSION}

An enhanced FLC-EMS has been introduced for a microgrid involves solar PV, FC and BES to satisfy the demand of a home. A simple FLC has been modeled only with 25 fuzzy rules. The system has been modeled mathematically and optimized using FA to provide better results in control strategy and energy saving potential. 
The simulations have been carried out in MATLAB. From the outcomes, it has been experienced that the energy saving potential has been enhanced by $10.97 \%$. The proposed approach can be easily implemented for any real-time system.

\section{REFERENCES}

1. G. Song, F. Ding, W. Zhang, and A. Song, "A wireless power outlet system for smart homes," IEEE Transactions on Consumer Electronics, vol. 54, no. 4, pp. 1688-1691, 2008.

2. A. Ikpehai, B. Adebisi, and M. K. Rabie, "Broadband PLC for Clustered Advanced Metering Infrastructure (AMI) Architecture," Energies, vol. 9, no. 7, 2016.

3. A. M. Ahmed, C. Y. Kang, and Y.-C. Kim, "Communication Network Architectures for Smart-House with Renewable Energy Resources," Energies, vol. 8, no. 8, 2015.

4. Z. Bradac, V. Kaczmarczyk, and P. Fiedler, "Optimal Scheduling of Domestic Appliances via MILP," Energies, vol. 8, no. 1, 2015.

5. M. Collotta and G. Pau, "A Novel Energy Management Approach for Smart Homes Using Bluetooth Low Energy," IEEE Journal on Selected Areas in Communications, vol. 33, no. 12, pp. 2988-2996, 2015.

6. J. Pascual, P. Sanchis, and L. Marroyo, "Implementation and Control of a Residential Electrothermal Microgrid Based on Renewable Energies, a Hybrid Storage System and Demand Side Management," Energies, vol. 7 , no. $1,2014$.

7. R. Subbiah, A. Pal, E. K. Nordberg, A. Marathe, and M. V. Marathe, "Energy Demand Model for Residential Sector: A First Principles Approach," IEEE Transactions on Sustainable Energy, vol. 8, no. 3, pp. 1215-1224, 2017.

8. N. Javaid et al., "A Hybrid Genetic Wind Driven Heuristic Optimization Algorithm for Demand Side Management in Smart Grid," Energies, vol. 10 , no. 3,2017

9. S. S. Khan, H. Shareef, A. Wahyudie, and S. N. Khalid, "Novel dynamic semiempirical proton exchange membrane fuel cell model incorporating component voltages," International Journal of Energy Research, vol. 42, no. 8, pp. 2615-2630, 2018/06/25 2018.

10. K. C. Udaiyakumar and M. Chandrasekaran, "Application of Firefly Algorithm in Job Shop Scheduling Problem for Minimization of Makespan," Procedia Engineering, vol. 97, pp. 1798-1807, 2014/01/01/ 2014.

\section{AUTHORS PROFILE}

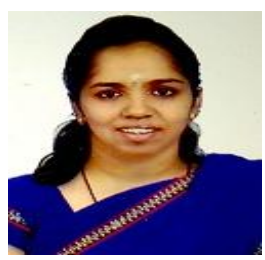

Ms. V. Nisha was born in Chennai, Tamil Nadu, India.

She received her UG degree in Electrical and Electronics Engineering from Sathyabama University, Chennai and M.E. degree in Power Electronics and Drives from Anna University, Chennai, Tamil Nadu, India, in 2015. Since September 2015, she has been working as an Assistant Professor in the Department of Electrical \& Electronics Engineering, Kalasalingam University, Krishnankoil, Virudhunagar District, Tamil Nadu and India. She has attended several international conferences and he has been actively involving herself in research since 2017. She has actively participated in various faculty development programs, symposiums, orientation programs, workshops and national seminars.

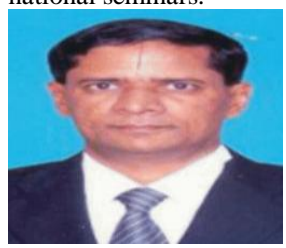

Dr.V. Vasudevan received Ph.D. degree in 1992. He is currently serving as Registrar and Senior Professor with the school of Computing and information sciences, Kalasalingam University, India. He has published 60 papers in International journals and International conferences. His current research interests include Distributed Computing, Grid Computing, Cloud Computing and Image Processing. He has large volume of publications in refereed journals. $\mathrm{He}$ is a life time member of Indian Society of Technical Education (ISTE).

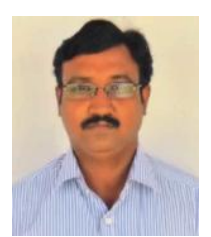

Dr. A. Ramkumar received the Ph.D degree from Kalasalingam Academy of Research andEducation in the year of 2014. He received the M.E (Power Systems) degree from Faculty of Engineering and Technology, Annamalai University, Chidambaram, Tamil Nadu, India, in2002 and received the B.E (Electrical and Electronics Engineering) from Thiagarajar Collegeof Engineering, M.K. University, Madurai, Tamil Nadu, India in the year of 1997. He hasbeen working as a Associate Professor in the Department of Electrical and ElectronicsEngineering, Kalasalingam Academy of Research and Education, Srivilliputhur, Tamil Nadu,since 2003. $\mathrm{He}$ is having more than 19 years' experience in the field of teaching. His researchinterests include Renewable Energy, Power System Planning, Power System Analysis, HighVoltage DC transmission Systems, Reactive Power Compensation, Flexible ACtransmissions Systems, Electrical Machines and Power System Automation. He is a Lifemember of ISTE and Member of IE(I). 